\title{
IMMUNOLOCALIZATION OF EXCRETORYISECRETORY ANTIGENS EXPRESSED ON DIFFERENT LIFE CYCLE STAGES AND IN DIFFERENT ORGANS OF FASCIOLA GIGANTICA INFECTED CATTLE
}

\author{
By \\ NEVEEN A. MADBOULY ${ }^{1 *}$, DOAA A. MOHAMED ${ }^{2}$, IBRAHEEM R. BAUIOMY ${ }^{2}$, \\ AND AZZA M. EL AMIR ${ }^{1}$
}

Department of Zoology, Faculty of Science, Cairo University ${ }^{1}$, and Department of Parasitology, Theodore Bilharz Research Institute ${ }^{2}$, Embaba P. O. Box 30, Giza, Egypt ('Correspondence: n_nevo_science@hotmail.com, Tel. +201099906863)

\begin{abstract}
In this study, polyclonal antibodies (pAb) were prepared against Fasciola gigantica excretory/ secretory $(\mathrm{E} / \mathrm{S})$ products and purified to demonstrate the highly reactive epitopes on the different life cycle stages of $F$. gigantica and on blood cells and different organs of naturally infected cattle, as well as to screen internal organs for localization of E/S antigens to find out a suitable method for diagnosing the disease as early as possible. Using anti- $F$. gigantica $\mathrm{E} / \mathrm{S} \operatorname{IgG} \mathrm{pAb}$, immunostaining of different life cycle stages of $F$. gigantica detected strong positive reactions in all stages except eggs. The reactions were along tegumental surface, gut region of cercariae, miracidiae, metacercariae and tail of cercariae. Besides, the tegument, spine surface, muscularis and gut region of the adults were also positive. Immunoperoxidase localization of $\mathrm{E} / \mathrm{S}$ products by anti- $F$. gigantica $\mathrm{E} / \mathrm{S} \operatorname{IgG} \mathrm{pAb}$ showed that $\mathrm{E} / \mathrm{S}$ antigens were located in many organs of naturally infected cattle. Examination of peripheral blood mononuclear cells (PBMNCs) represented a high positivity in the phagosomes and activated monocytes as well as in cytoplasm of lymphocytes. Compared to sections of normal uninfected hosts, liver sections of infected bovine hosts showed collapsed hepatocytes, thickened portal tract and a highly positive reaction in the cytoplasm of the liver cells. Target epitopes were located inside the splenic cells, mainly lymphocytes. In the gall bladder, positive peroxidase reactions were found in the mucosa and muscularis layers, and in the epithelial cells lining mucosal glands. A marked positivity was in other organs of the naturally infected animals, as in the epithelial layer lining the glomeruli and tubules of the kidney, in heart cardiac muscle fibres and in cells lining the alveoli of the lungs.

Key words: Fasciola gigantica, excretory secretory products, polyclonal antibodies, life cycle stages of worms, host bovine organs, immunolocalization
\end{abstract}

\section{Introduction}

The trematodes Fasciola are a causative agent of liver fluke disease which has a worldwide distribution and results in major economic losses in agricultural communities (Mas-Coma and Bargues, 1997). These are the most common liver flukes in cattle, sheep, goats and other herbivorous mammals (Rttier and Ince, 2003). However, the human fascioliasis increased dramatically all over the world and not necessarily related to areas endemic for the animal disease (Esteban et al, 2002; Mas-Coma, 2004; 2005; Keyyu et al, 2006) where fascioliasis chronicity and superimposed repetitive liver fluke infections pose additional pathological complications (Valero et al, 2003; Saba et al, 2004; Dauchy et al, 2006; Shirai et al,
2006). In Egypt, Haseeb et al. (2002) reported that fascioliasis caused $30 \%$ loss in both meat and milk production of veterinary outcome/year. WHO (1995) estimated that 830,000 people are infected with liver flukes in the Nile Delta region of Egypt (Haridy and Morsy, 2000; Esteban et al, 2003; ElShazly et al, 2005). The fascioliasis clinical manifestations in man were fever, abdominal pain, persistent diarrhea, vomiting and eosinophilia. Fascioliasis can be differentially from other diseases as acute hepatitis, schistosomiasis, visceral toxocariasis, biliary tract diseases and hepatic amoebiasis (Keyyu et $a l$, 2006; Ganga et al, 2007). So, early diagnosis was a must to start treatment and to avoid complications (Hillyer et al, 1992).

Parasitological diagnosis of infection was 
by identification of $F$. gigantica/hepatica eggs in fecal samples (Barreto et al, 1990). Since eggs appeared in the feces only after the parasite entered the bile duct and matured [10-14 weeks post infection (wk PI)], early infection cannot be diagnosed by detecting coproantigens (Armour et al, 1997). In addition, because eggs were released sporadically from the bile ducts, an accurate diagnosis by this method required at least three stool samples obtained at different times on consecutive days (Haseeb et al, 2002). Serodiagnosis of fascioliasis was developed for specific antibodies detection at 2-4wk PI, against $\mathrm{Ag}$ derived from adult fluke extracts or their E/S products (Espinoza et al, 2007; Sarkari and Abdolahi Khabisi, 2017). But, cross reactivity with other parasites was reported that decreased its specificity (Bo-ssaret et al, 2000). Ideally, a diagnostic test for Fasciola infection should be as early as possible and based on circulating Fasciola Ags detection, using Abs that did not react except with the target antigens. Another approach was based on the detection of spe-cific antigens in serum (Attallah et al, 2013), and in urine or feces of infected host (Du-menigo et al, 1996). As coproantigens, cannot be detected until 6wk PI (Abdel Rahman et al, 1998), the antigenimia caused at about 810wk PI was due to the immune complexes formation (Castro et al, 2000). E/S antigens are probably composed of molecules released from the continuous turnover of the glycocalyx coating the tegument surface membrane as well as some enzymes released from the caecum. The E/S antigens did not only have an important role in the induction of protective immunity but contained antigens useful for immunodiagnosis of fascioliasis (El-Kerdany et al, 2002). Antibodies (Abs) to E/S antigens can be detected as early as 2 wk and peak concentrations are reached at 8-10wk PI (Fagbemi and Guobadia, 1995; Novobilský et al, 2007). Monoclonal antibodies series of (mAbs) were prepared against tegumental and internal antigens of $F$. hepatica by immunizing mice with whole adult homogenates (Chaithirayanon et al, 2002). Screening of $F$. hepatica tegumental antigens by using indirect immunoflorescence antibody technique (IF) was developed (Hanna et al, 1988). By the application of peroxidase immunostaining technique (David and Dabbs, 2000), with a possible distribution map of $F$. gigantica antigens expressed in all parasite developmental stages (Cancela et al, 2004), and the blood and different organs of naturally infected cattle that was a strong candidate for immuno-diagnosis and vaccine development against fascioliasis.

This study aimed to screen the internal organs for localization of anti- $F$. gigantica $\mathrm{E} / \mathrm{S} \operatorname{IgG}$ $\mathrm{pAb}$, immunostaining antigens to find a suitable method for zoonotic fascioliasis early diagnosis

\section{Materials and Methods}

New Zealand white male rabbits $(\approx 3 \mathrm{~kg})$, about 4 months old, were purchased from the Schistosome Biological Supply Program, Theodore Bilharz Research Institute (SBSP, TBRI), Giza. They were kept under standard laboratory care at $21^{\circ} \mathrm{C} \& 16 \%$ moisture and provided with filtered drinking water and diet (15\% protein, $3 \%$ fat \& $22 \%$ fibres).

Adult $F$. gigantica worms were collected out of biliary tracts and gall bladders of fresh infected bovine livers at a slaughterhouse. The live intact worms were washed many times with phosphate-buffered saline (PBS, $\mathrm{pH}$ 7.4). Life cycle stages (eggs, miracidiae, cercariae and metacercariae) were purchased from SBSP, TBRI.

Antigen preparation: Mature $F$. gigantica flukes were incubated for $16 \mathrm{hr}$ at $37^{\circ} \mathrm{C}$ in RPMI 1640 (pH 7.3) (Sigma), contained 2\% glucose, 30mM HEPES (N-2-hydroxyethylpiperazine-N-2 ethanesulphonic acid) and $25 \mathrm{mg}$ of gentamycin (Sigma). The suspension was centrifuged at $14,900 \mathrm{~g}$ for $30 \mathrm{~min}$ and the supernatant $(\mathrm{E} / \mathrm{S})$ was collected and stored at $-20^{\circ} \mathrm{C}$ as aliquots until used (Maleewong et al, 1999). The protein content of E/S antigens was measured by the Bio-Rad protein assay kit (BradFord, 1976).

Immunization: Blood samples were taken from rabbit ears before experiment, and exa- 
mined by indirect ELISA for Fasciola antibodies and cross reaction with other parasites. Each rabbit received an intramuscular (i.m.) injection as $1 \mathrm{mg}$ of $F$. gigantica $\mathrm{E} / \mathrm{S}$ antigens mixed with equal volume of complete Freund's adjuvant (CFA, Pierce, Rockford, IL, USA). Booster doses $(0.5 \mathrm{mg}$ E/S in equal volume of incomplete Freund's adjuvant (IFA, Pierce) was administered at 2, $3 \&$ 4wk after the initial dose (Fagbemi et al, 1995). Individual sera were collected 4 days after the last injection.

Purification and IgG pAb labeling (Nowotny, 1979): Purification of anti-Fasciola IgG $\mathrm{pAb}$ sera were performed by ammonium sulphate precipitation after treatment with caprilic acid treatment (Mckinney and Parkinson, 1987). Purified anti-E/S F. gigantica was electrophoresed on SDS-PAGE (Harlow and Lane, 1988; Myers (1995). Testing for reactivity and specificity of pAb against different concentrations of $F$. gigantica $\mathrm{E} / \mathrm{S}$ antigens was done by modified indirect ELISA (Engvall and Perlman, 1971). Standardization of serial dilutions $(2.5,5,10,20 \& 30$ $\mu \mathrm{g} / \mathrm{ml}$ ) of purified $\mathrm{pAb}$ was done by sandwich ELISA. Labeling of $\mathrm{pAb}$ was done with horseradish peroxidase (HRP) using periodate technique (Tijssen and Kurstak, 1984).

Preparation of $F$. gigantica life cycle stages: Different stages of $F$. gigantica life cycle (eggs, miracidiae, cercariae \& meta-cercariae) were incubated individually for $24 \mathrm{hr}$ in dechlorinated water till sedimented. Sediment was fixed in a mixture of equal volumes of $4 \%$ buffered glutaraldehyde and $0.2 \mathrm{M}$ cacodylate for $1 \mathrm{hr}$. Mixture was put in a $3 \mathrm{~mm}$ hole of $1.5 \%$ hardened gelose layer followed by another liquefied gelose layer to form blocks was refixed in $10 \%$ formalin buffer to prepare $5 \mu$ paraffin sections (Mansy, 2004).

Preparation of PBMNCs and different organs of infected cattle: PBMNCs were separated using Ficol Hepaque (Seramid Biochrom, Berlin), and blood slides were prepared for immunostaining application. Parts of liver, spleen, gall bladder, intestine, kidney, heart and lung were isolated from 10 infected slaughtered cattle and fixed in 10\% buffered formalin for $24 \mathrm{hr}$, processed in Department of Pathology in TBRI.

Immunolocalization of Fasciola E/S antigens: Prepared slides were immersed over night in xylene. Except PBMNCs slides, all slides were transferred into graded ethanol $(100,95, \& 70 \%)$; 5min each, washed with distilled water (Dist. $\mathrm{H}_{2} \mathrm{O}$ ) for $2 \mathrm{~min} \&$ with $0.05 \mathrm{M}$ Tris buffer saline (TBS) for $5 \mathrm{~min}$. To block endogenous peroxidase, slides were incubated for $30 \mathrm{~min}$ in $3 \% \mathrm{H}_{2} \mathrm{O}$ in methanol. HRP-pAb conjugate [diluted 1:250 with $1 \%$ bovine serum albumin (BSA)], was added and incubated in $3 \% \mathrm{H}_{2} \mathrm{O}$ for $24 \mathrm{hr}$ at room temperature. Sections were washed and incubated in dark with diaminobenzidine tetra hydrochloride (DAB) substrate (Sigma) for $1 \mathrm{hr}$ at room temperature. Reaction was stoped with Dist. $\mathrm{H}_{2} \mathrm{O}$. Sections were dehydrated in $70,90 \& 100 \%$ ethanol for $5 \mathrm{~min}$ each, washed 3 times in TBS, and stained with Mayer's hematoxylin for $2 \mathrm{~min}$, washed with tap water and mounted in Canada balsam (Bancroft and Gamble, 2002).

\section{Results}

By using 12.5\% SDS-PAGE technique under reduced condition, 50\% ammonium sulphate precipitated protein showed that most albumin was removed from rabbit anti-Fasciola $\mathrm{E} / \mathrm{S}$ products $\mathrm{pAb}$. Precipitated proteins appeared as several bands. More purification of the whole Igs by $7 \%$ caprilic acid precipitation removed remaining non-IgG proteins. Purified IgG was represented by $\mathrm{H}-$ $\& \mathrm{~d}$ L- chain bands at $53 \& 31 \mathrm{kDa}$, respectively (Fig. 1).

Reactivity of $\mathrm{pAb}$ against $F$. gigantica $\mathrm{E} / \mathrm{S}$ was determined by indirect ELISA and showed strong reactivity to $F$. gigantica $\mathrm{E} / \mathrm{S}$ $2.622 \mathrm{OD}$ reading at $492 \mathrm{~nm}$ without cross reactivity to other parasitic antigens mainly Schistosoma antigens.

Optimum concentration of purified $\operatorname{IgG}$ $\mathrm{pAb}$ was $20 \mathrm{mg} / \mathrm{ml}$, and conjugated $\mathrm{IgG}$ pAb was 1:250 dilutions. Immunolocalization technique by using anti- $F$. gigantica $\mathrm{E} / \mathrm{S}$ showed no specific peroxidase reactions in $F$. 
gigantica eggs (Fig. 2). A positive reaction was on tegumental surface and gut region of miracidiae, cercariae and metacercariae (Figs. 3, 4 \& 5). A strong reaction was only against cephalic and tail regions of cercariae (Fig. 4). Immuno-staining of Fasciola adults showed intense positive brown color along tegument, spine surface, muscularis and gut region (Fig. 6).

Infected liver sections showed a loss of hepatic lobular architecture, damage of hepatocytes, interlobular fibrosis, central calcification and abscess formation. Positive peroxidase reactions (10 cases) were in cytoplasm of liver cells, histiocytes in interlobular lesions and necrotic foci of hepatocytes and Kupffer cells (Fig. 7b), as compared to normal one (Fig. 7a). Infected gallbladder sections showed hyperplasia of mucosal lining with focal erosions led to walls thickening. Lamina was infiltrated by a moderate number of lymphocytes and eosinophils accumulations (Fig. 8a). A positive peroxidase reaction (10 cases) was in cytoplasm of cell lining, in muscularis and mucosa layers compared to normal one (Fig. 8a).

Small intestine sections of infected cattle showed focal superficial erosion of epithelial cells lining the mucosal glands. The submucosa was infiltrated with moderate numbers of lymphocytes with mild reformed blood vessels. Post immunostaining with anti$F$. gigantica $\mathrm{E} / \mathrm{S} \mathrm{IgG} \mathrm{pAb}$, a positive peroxidase reaction ( 8 cases) was in epithelial cells lining mucosal glands (Fig. 9b) as compared to normal uninfected one (Fig. 9a).

Kidney sections of infected cattle showed that tubules and glomeruli were infiltrated by mild numbers of inflammatory cells, thick walls and basement membranes. Post immunostaining with anti- $F$. gigantica $\mathrm{E} / \mathrm{S} \mathrm{IgG}$ $\mathrm{pAb}$, a positive peroxidase reaction ( 7 cases) was in the cytoplasm of epithelial cells lining glomeruli and tubules of kidney (Fig. $10 \mathrm{~b}$ ) as compared to normal one (Fig. 10a).
Spleen showed splenomegaly and sections showed a proliferation of solenocytes and lymphocytes. Post immunostaining with anti- $F$. gigantica $\mathrm{E} / \mathrm{S}$ IgG pAb showed a positive peroxidase reaction ( 7 cases) as intracytoplasmic brownish granules in splenic lymphocytes (Fig. 11b) as compared to normal ones (Fig. 11a).

Infected lungs sections showed thickened walls of alveoli with mild infiltration of lymphocytes and plasma cells. Post immunostaining with anti- $F$. gigantica $\mathrm{E} / \mathrm{S}$ IgG pAb, showed a positive peroxidase reaction (6 cases) in cells lining alveoli (Fig. 12b) as compared to normal one (Fig. 12a). Cardiac muscle fibres were infiltrated by moderate number of lymphocytes, plasma cells and eosinophils. Post immunostaining with anti- $F$. gigantica $\mathrm{E} / \mathrm{S}$ IgG $\mathrm{pAb}$, a positive peroxidase reaction ( 5 cases) was in the cytoplasm of cardiac muscle fibres (Fig. 13b) as compared to normal one (Fig. 13a).

Examination of PBMNCs of normal cattle showed normal monocytes with a nucleus occupying about half area of the cell that was uniform and eccentrically placed, while cytoplasm was spread out. Monocytes of infected cattle showed a marked activation by significant increase of cell size and extended monocytes pseudopodia. Immunoperoxidase localization of $\mathrm{E} / \mathrm{S}$ products by anti- $F$. gigantica $\mathrm{E} / \mathrm{S}$ IgG pAb showed a high cytoplasmic organelles positivity in activated monocyte (Fig. 14b), without reaction in normal one (Fig. 14a). Normal lymphocytes were ovoid or kidney-shaped nucleus with densely packed nuclear chromatin with a cytoplasmic rim. Lymphocytes infected cattle showed a marked activation by an increase of cytoplasm with a significant increase of vacuoles. Immunoperoxidase localization of $\mathrm{E} / \mathrm{S}$ by anti- $F$. gigantica $\mathrm{E} / \mathrm{S}$ IgG pAb was in cytoplasm of vacuolated lymphocytes (Fig. $15 \mathrm{~b}$ ), but without reaction in normal one (Fig. 15a). 


\section{Discussion}

Fascioliasis is a zoonosis caused by $F$. hepatica \& $F$. gigantica with a worldwide distribution causing major economic losses (Aksoy et al, 2005). Sheep, goats, cattle, camels, deer, horses, and rabbits are definitive hosts with about 2.4 million people infected worldwide and 180 million at risk (Kamel and Lumely, 2004).

Many serological tests were available for diagnosis but, with low specificity due to cross-reactivity with parasitic antigens (AbdelRahman et al, 2000; Attalah et al, 2002). Fasciola species release different antigenic components at different development stages in mammalian hosts (Morphew et al, 2007). Several F. gigantica Ags with immunodiagnostic potential were identified in flukes' preparations and their E/S products (Espino and Finaly, 1994). E/S antigens contained many enzymes such as glutathione S-transferase (GST), cysteine proteinase and cathepsin L (CL) proteinases (Neyra et al, 2002; Ruis et al, 2003; Collins et al, 2004; Kesik et al, 2007) and actin, the glycolytic enzyme enolase and glyceralde-hydes-3P-dehydrogenase (Morphew et al, 2007). Others repported the thioredoxin reductase in the E/S products from adult worms (Salazar-Calderon et al, 2001; Maggioli et al, 2004), indicating the release of the protein either by active secretion or due to rapid turnover of surface coat. No doubt, E/S antigens formed immune complexes with host antibodies to fascioliasis (El-Kerdany et al, 2002; El Amir et al, 2020). F. hepatica $\mathrm{E} / \mathrm{S}$ products were key players to understand the host-parasite interaction and gave targets for chemo- and immuno-therapy (Morphew et al, 2007).

In the present study, pAb against Fasciola $\mathrm{E} / \mathrm{S}$ antigens demonstrated the presence of highly reactive epitopes on the different life cycle stages of $F$. gigantica as well as on the different organs and PBMNCs of naturally infected cattle. Immunolocalization of antigenic epitopes on different components of $F$. gigantica life cycle stages was studied (Kha- wsuk et al, 2002; Cancela et al, 2004; Tansatit et al, 2006). Also, the studied, immunoperoxidase techniques utilized the presence of E/S products in adult and in developmental stages. Immunostaining of Fasciola adult elicited an intense positive brown color along the tegument, spine surface, muscularis and gut region. The dense-stained granules were spreading throughout the tegumental cytoplasm and in the tegumental cell lying beneath the muscle layer. This agreed with Viyanant et al. (1999) using mAb that reacted specifically with the E/S antigens and found intense staining of the luminal content and epithelial cells lining caecum of adult worms. Attallah et al. (2002) studied labelled $\mathrm{pAb}$ against $26-28 \mathrm{kDa}$ band of $F$. gigantica $\mathrm{E} / \mathrm{S}$ antigen in adults and different organs of infected cattle, found a positive immunoperoxidase staining in fluke sections of tegument, muscularis and gut cells.

In the present study, immunolocalization showed no staining of egg. Positive staining was in tegumental surface and gut region of miracidiae, cercariae and metacercariae with a strong positive one against cephalic and tail regions of cercariae and metacercarial parenchymal tissue. This agreed with Khawsuk et al. (2002) used thioredoxin and Anuracpreeda et al. (2006) used mAb against recombinant enzymes as glutathione-S-transferase. Also, positive peroxidase reactions were in cytoplasm of liver cells, histiocytes in interlobular lesions and necrotic foci of hepatocytes and Kupffer cells that agreed with Tanimoto et al. (1998); Attallah et al. (2002) and Gajewska et al. (2005), who found a positive peroxidase reaction in cytoplasm of liver cells, and muscularis of gallbladder.

In the present study, a positive peroxidase reaction was in epithelial cells lining intestinal mucosal glands and renal glomeruli and tubules. Kidney tissue showed a mild infiltration of chronic inflammatory cells (especially lymphocytes). This agreed with Marques et al. (2004) who found an association between fascioliasis and glomerulopathy due 
to immune complexes.

In the present study, immunoperoxidase techniques in infected cattle showed positive peroxidase reaction in the cells lining lung alveoli and cardiac muscle fibres. This agreed with President et al. (1974) who found a granuloma on left lung dorsal border and inflammatory cells accumulation in a track associated with fluke in epicardium of $F$. hepatica infected white-tailed deer. Also, the PBMNCs from infected cattle showed high positivity in phagosomes, activated monocytes and cytoplasm of lymphocytes, which agreed with Intapan et al. (2005), Wongkham et al. (2005) and Mezo et al. (2007) who diagnosed sheep fascioliasis by $\mathrm{E} / \mathrm{S}$ antigens in infected blood.

\section{Conclusion}

E/S antigens released from Fasciola surface, intestine and blood system, as membrane-bound antigens, expressed in all developmental stages and in different organs of naturally infected cattle. It proved as a candidate for immuno-diagnosis and vaccine development. E/S antigens, especially in blood helped in early fascioliasis diagnosis.

Author contributions: All authors equally contributed in this work.

\section{References}

Abdel-Rahman, EH, Abdel-Megged, KN, Hassanain, MA, 2000: Structural characterization and immunolocalization of egg antigens crossreact with Toxocara vitulorum, Fasciola gigantica and Moneiza expansa mature flukes. J. Egypt. Soc. Parasitol. 30:581-91.

Abdel-Rahman, S, O'Reilly, KL, Malone, JB, 1998: Evaluation of a diagnostic monoclonal antibody-based capture ELISA for detection of a $26-\mathrm{kDa}$ to $28-\mathrm{kDa}$ Fasciola hepatica coproantigens in cattle. Am. J. Vet. Res. 59:533-7.

Aksoy, D, Kerimoglu, U, Oto, A, Erguven, S, Arslan, S, et al, 2005: Infection with $F$. hepatica. Clin. Microbiol. Infect. 1:859-61.

Anuracpreeda, P, Wanichanon, C, Chaithirayanon, K, Preyavichyapugdee, N, Sobhon, $P$, 2006: Distribution of $28.5 \mathrm{kDa}$ antigen in the tegument of adult Fasciola gigantica. Acta Trop. 100:31-40.

Armour, J, Urqhart, GM, Ductan, JL, 1997: Veterinary Parasitology, $2^{\text {nd }}$ ed. Oxford: Black- well Science Ltd.

Arora, DR, Arora, B, 2005: Trematodes a flukes. In: Medical Parasitolgy, $2^{\text {nd }}$ edition, Satich Kumar Jain for CBS Publishers \& Distributors, New Dehli. Banalore (India).

Attallah, AM, Karawia, EA, Ismail, H, Tabll, AA, Nawar, AA, et al, 2002: Identification and characterization of 26- to 28- $\mathrm{kDa}$ circulating antigen of $F$. gigantica. Ann. Trop. Med. Parasitol. 96:271-82.

Attallah, AM, Bughdadi, FA, El-Shazly, AM, Ismail, H, 2013: Immunodetection of Fasciola gigantica circulating antigen in sera of infected individuals for laboratory diagnosis of human fascioliasis. Clin. Vacc. Immunol. 20:1569-77.

Bancroft, JD, Gamble, M, 2002: Theory and Practice of Histological Techniques. $5^{\text {th }}$ edition. London.

Barreto, ML, Smith, DM, Sleigh, AC, 1990: Implication of fecal egg count variation when using the Kato-Katz method to assess Schistosoma mansoni infection Trans. R. Soc. Trop. Med. Hyg. 84:554-5.

Bossaret, K, Farnir, F, Leclipteux, T, Protz, M, Lonneux, JF, et al, 2000: Humoral immuneresponse in calves to single-dose, trickle and challenge infections with Fasciola hepatica. Vet. Parasitol. 87:103-23.

Bradford, MM, 1976: A rapid and sensitive method for the quantitation of microgram quantities of protein utilizing the principle of proteindye binding. Anal. Biochem. 72:248-54.

Cancela, M, Carmona, C, Rossi, S, Frangione, B, Goñi, F, et al, 2004: Purification, characterization, and immunolocalization of paramyosin from the adult stage of Fasciola hepatica. Parasitol. Res. 92:441-8.

Castro, E, Freyre, A, Hernandez, Z, 2000: Serological responses of cattle after treatment and during natural reinfection with Fasciola hepatica, as measured with dot-ELISA system. Vet. Parasitol. 90: 201-8.

Collins, PR, Stack, CM, O'Neill, SM, Doyle, S, Ryan, T et al, 2004: Cathepsin L1, the major protease involved in liver fluke (Fasciola hepatica) virulence. J. Biol. Chem. 17:17038-46.

Dauchy, F.A.Vincendeau, P, Lifermann, F, 2006: Eight cases of fascioliasis: clinical and microbiological features. Med. Mal. Infect. 36:

42-6.

David, J, Dabbs, MD, 2000: Diagnostic Immunohistochemistry. Vol. 1, New York, London. Dumenigo, BE, Espino, AM, Finlay, C, 1996: 
Detection of $F$. hepatica antigen in cattle feces by a monoclonal-based sandwich immuno-assay. Res. Vet. Sci. 60:278-9.

EL Amir, AM, Farid, AA, Mohamed, M, Ramadan, W, Diab, AA, 2020: The efficacy of Dizygtheca kerchoveana and Azadirachta indica extracts as a molluscicidal and schistosomicidal agents in mice. J. Egypt. Soc. Parasitol. 50, 1: 91-8.

El-Kerdany, ED, Abd-Alla, NM, Sharaki, O A, 2002: Recognition of antigenic components of Fasciola gigantica their use in immunodiagnosis. J. Egypt. Soc. Parasitol. 32, 3:675-90.

El-Shazly, A, Abdel-Magied, A, El-Nahas, H, 2005: On the main reservoir host of a Fasciola in Dakahlia Governorate, Egypt. J. Egypt. Soc. Parasitol. 35:243-52.

Engvall, E, Perlman, P, 1971: Enzyme linked immunosorbent assay (ELISA): Quantitative assay of characterization. J. Immunochem. 8:8714.

Esteban, J, Gonzalez, C, Bargues, M, 2002: High fascioliasis infection in children linked to a man-made irrigation zone in Peru. Trop. Med. Int. Hlth. 7:339-48.

Esteban, JG, Gonzalez, C, Curtale, F, 2003: Hyperendemic fascioliasis associated with schistosomiasis in villages in the Nile Delta of Egypt. Am. J. Trop. Med. Hyg. 69:429-34.

Fagbemi, BO, Guobadia, EE, 1995: Immunodiagnosis of fascioliasis in ruminants by $28-\mathrm{kDa}$ cysteine protease of $F$. gigantica adult worm. Vet. Parasitol. 57:309-18.

Fagbemi, BO, Obarisiagbon, IO, Mbuh, JV, 1995: Detection of circulating antigen in sera of Fasciola gigantica infected cattle with antibodies reactive with a Fasciola-specific $88-\mathrm{kDa}$ antigen. Vet. Parasitol. 58:235-46.

Gajewska, A, Smaga-Kozlowska, K, Wisniewski, M, 2005: Pathological changes of liver in infection of Fasciola hepatica. Wiad. Parazytol. 51:115-23.

Ganga, G.Varshney, JP, Sharma, RL, Varshney, VP, Kalicharan, A, 2007: Effect of Fasciola gigantica infection on adrenal and thyroid glands of riverine buffaloes. Res. Vet. Sci. 82: 61-7.

Hanna, RE, Trudgett, AG, Anderson, A, 1988: $F$. hepatica: development of monoclonal antibodies against somatic antigens and their characterization by ultrastructural localization of antibody binding. J. Helminthol. 62:15-28.

Haridy, FM, Morsy, TA, 2000: Camel: A new
Egyptian host for Fasciola gigantica. J. Egypt. Soc. Parasitol. 30, 2:451-4.

Harlow, E, Lane, D, 1988: Antibodies, Laboratory Manual. Cold Spring Harbor Laboratory, New York.

Haseeb, AN, EL Shazly, AM, Arafa, MA, Morsy, ATA, 2002: A review on fascioliasis in Egypt. J. Egypt Soc. Parasitol. 32, 2:317-54.

Hillyer, GV, Galanes, M, Rodriguez-Perez, J, Bjorland, J, Lagrava, M, et al, 1992: Use of the Falcon assay screening test-enzyme-linked immunosorbent assay (FAST-ELISA) and enzyme linked immunoelectrotransfer blot (EITB) to determine the prevalence of human fascioliasis in the Bolivian Altiplano. Am. J. Trop. Med. Hyg. 46:603-9.

Tantrawatpan, C, Maleewong, W, Wongkham, S, Wongkham, C, Nakashima, K, 2005: Potent epitopes derived from Fasciola gigantica cathepsin L1 in peptide-based immunoassay for the serodiagnosis of human fascioliasis. Diagn. Microbiol. Infect. Dis. 53:125-9.

Kamel, R, Lumely J, Abaza H, 2004: Fascioliasis, In: Text book of Tropical Surgery Parasitology. Vol. 2: Westminister Ltd, London.

Khan, M, Ullah, R, Rehman, A, Rehman, L, Shareef, AP, et al, 2017: Immunolocalization and immunodetection of the excretory/secretory (ES) antigens of Fasciola gigantica. PLOS One 12, 10: e0185870.

Jedlina-Panasiuk, L, Kozak-Cieszczyk, M, Płucienniczak, A, Wedrychowicz, H, 2007: Enteral vaccination of rats against Fasciola hepatica using recombinant cysteine proteinase (cathepsin L1). Vaccine 25:3619-28.

Khawskuk, W, Soonklang, N, Grams, R, Vichasri-Grams, S, Wanichanon, $C$, et al, 2002: Production and characterization of a monoclonal antibody against recombinant GST of $F$. gigantica. Asian Pac. J. Aller. Immunol. 20:257-66.

Keyyu, JD, Kassuku, AA, Msalilwa, LP, 2006: Cross-sectional prevalence of helminthic infections in cattle on traditional, small-scale and large-scale dairy farms in Iringa District, Tanzania. Vet. Res. Commun. 30:45-55.

Maggioli, G.Piacenza, L, Carambula, B, Carmona, C, 2004: Purification, characterization, \& immunolocalization of a thioredoxin reductase from adult $F$. hepatica. J. Parasitol. 90:205-11. Maleewong, W, Wongkham, C, Intapan, PM, Pipitgool, V, 1999: Fasciola gigantica- specific antigens: Purification by a continuous-elution method and its evaluation for diagnosis of hum- 
an fascioliasis. Am. J. Trop. Med. Hyg. 61:64855.

Marcos, L, Saez, S, Neyra, V, Terashima, A, Samalvides, F, et al, 2007: Evaluation of Fas2ELISA for the serological detection of Fasciola hepatica infection in humans. Am. J. Trop. Med. Hyg. 76:977-82.

Mansy, S, 2004: Agarose cell block: Innovated technique for the processing of urine cytology for electron microscopic examination. Ultrastruct. Pathol. 28:15-21.

Marques, S, Scroferneker, ML, Edelweiss, M I, 2004: Glomerulonephritis in water buffaloes (Bubalus bubalis) naturally infected by $F$. hepatica. Vet. Parasitol. 123:83-91.

Mas-Coma, S, 2004: Human fascioliasis. In: Waterborne Diseases: Identification, Causes and Control. Cotruvo, J, Dufour, A, Rees, G, et al. (Eds.): WHO, IWA Publishing, London, UK.

Mas-Coma, S, 2005: Epidemiology of fascioliasis in human endemic areas. J. Helminthol. 79: 207-16.

Severin, K, Martinković, F, Simpraga, M, Janicki, Z, Barišić, J, 2007: Hematological and biochemical changes in organically farmed sheep naturally infected with Fasciola hepatica. Parasitol Res. 101:1657-61.

Mckinney, MM, Parkinson, A, 1987: A single, non-chromatographic procedure to purify immunoglobulins from ascites fluid. J. Immunol. Meth. 96:271-8.

Myers, RL, 1995: Immunology a laboratory manual. In: Animal and Human Immunoglobulins. $2^{\text {nd }}$ ed. Academic Press, New York.

Neyra, V, Chavarry, E, Espinoza, J, 2002: Cysteine proteinases Fas1 and Fas2 are diagnostic marker for $F$. hepatica infection in alpacas, Vet. Parasitol. 105:21-32.

Novobilský, A, Kasný, M, Mikes, L, Kovarcík, K, Koudela, B, 2007: Humoral immune responses during experimental infection with $F$. magna and $F$. hepatica in goats and comparison of their E/S products. Parasitol. Res. 101:35764.

Nowotny, A, 1979: Basic Exercises in immunochemistry. Springer Verlag, Berlin Heidelberg. New York.

President, PJ, McCraw, BM, Lumsden, S, 1974: Early pathological changes associated with Fasciola hepatica infection in white-tailed deer. Can. J. Comp. Med. 38:271-9.

Rodriguez-Perez, J, Hillyer, GV, 1995: Detection of E/S circulating antigens in sheep infected with $F$. hepatica and with $S$. mansoni and $F$. hepatica. Vet. Parasitol. 56:57-66.

Rttier, E, Ince, M, 2003: Controlling and preventing disease. In: The Role of Water and Sanitation Interventions. WEDC; Loughborough University, UK.

Ruis, A, Molna, JM, Gonzalez, J, MartinezMoreno, FJ, Gutierrez, PN, et al, 2003: Humoral response of goats experimentally infected with $F$. hepatica against cysteine proteinase of adult fluke. Vet. Res. 34:435-43.

Saba, R, Korkmanz, M, Inan, D, 2004: Human fascioliasis. Clin. Microbiol. Infect. 10:385-4. Salazar-Calderon, M, Martin-Alonso, J, Ruiz, A, Parra, F, 2001: Heterologous expression and functional characterization of thioredoxin from F. hepatica. Parasitol. Res. 87:390-5.

Sarkari, B, Abdolahi Khabisi, S, 2017: Immunodiagnosis of human fascioliasis: An update of concepts and performances of the serological assays. J. Clin. Diagn. Res. 11:5-10.

Shirai, W, Sato, T, Shibuya, H, Naito, K, Tsukise, A, 2006: Anatomico-pathological study of vascular and biliary systems using cast samples of Fasciola-infected bovine livers. J. Vet. Med. Physiol. Pathol. Clin. Med. 53:239-45.

Tanimoto, T, Shirota, K, Ohtsuki, Y, Araki, K, 1998: Eosinophilic proliferative pylephlebitis in the liver of Japanese beef cattle with fascioliasis. J. Vet. Med. Sci. 60:1073-80.

Tansatit, T, Sahaphong, S, Riengrojpitak, S, Viyanant, V, Sobhon, P, 2006: Immunolocalization of cytoskeletal components in the tegument of the 3-week-old juvenile and adult Fasciola gigantica. Vet. Parasitol. 135:269-78.

Tijssen, P, Kurstak, P, 1984: Highly efficient and simple methods for the preparation of peroxidase and active peroxidase-antibody conjugate for enzyme immunoassays. Anal. Biochem. 136: 451-7.

Valero, MA, Santana, M, Morales, M, Hernandez, JL, Mas-Coma, S, 2003: Risk of gallstone disease in advanced chronic phase of fascialiasis: An experimental study in a rat model. J. Infect. Dis. 188:787-93.

Viyanant, V, Upatham, ES, Sobhon, P, Krailas, D, Ardseungnoen, $P$, et al, 1999: Development and characterization of monoclonal antibodies against $\mathrm{E} / \mathrm{S}$ antigens of $F$. gigantica. SouthEast Asian J. Trop. Med. Pub. Hlth. 28:128-33. Wanichanon, CK, Grams, S, Ardseungneon, P, Grams, R, et al, 2002: Production and characterization of a mAb against $28.5 \mathrm{kDa}$ tegume- 
nt antigen of F. gigantica. Acta Trop. 84:1-8. WHO, 1995: Control of food-borne trematode infections. WHO Expert Committee, Tech. Rep. No. 849, Geneva, Switzerland. Wongkham, C, Tantrawatpan, C, Intapan, $P$

\section{Explanation of figures}

Fig 1: 12.5\% SDS-PAGE of anti-F. gigantica E/S pAb stained with Coomassie blue, Lane 1: Mw standard proteins, Lane 2: Crude anti- $F$. gigantica $\mathrm{E} / \mathrm{S}$ IgG pAb, Lane 3: Precipitated proteins after 50\% ammonium sulfate treatment \& Lane 4: Purified IgG pAb after 7\% caprylic acid treatment.

Fig 2: F. gigantica eggs (a) Negative control slide without anti-F. gigantica E/S IgG pAb. (b) Section with anti-F. gigantica E/S IgG pAb., without positive staining of egg on either section (Immunostained, DAB x400).

Fig 3: (a) F. gigantica miracidiae showed negative peroxidase reactions. (b) Immunoperoxidase localization of E/S products by anti- $F$. gigantica $\mathrm{E} / \mathrm{S}$ IgG pAb on $F$. gigantica miracidiae showed a positive peroxidase reaction visualized on the tegumental surface (small arrow) and gut (large arrow) of miracidiae (Immunostained, DAB x400).

Fig 4: (a) F. gigantica cercariae showed a negative peroxidase reaction. (b) Immunoperoxidase localization of E/S products by anti- $F$. gigantica $\mathrm{E} / \mathrm{S}$ IgG pAb of $F$. gigantica cercariae showed a positive peroxidase reaction along tegumental surface of cercariae (large arrow) and same reaction in gut cells (head arrow) and tail (small arrow) (Immunostained, DAB x400).

Fig 5: (a) F. gigantica metacercariae showed a negative peroxidase reaction. (b) Immunoperoxidase localization of E/S products by anti- $F$. gigantica $\mathrm{E} / \mathrm{S}$ IgG pAb of $F$. gigantica metacercariae section showed intense positive brown color mainly in tegument (arrow) and gut region $(\mathrm{g}), \&$ parenchymal tissue $(\mathrm{p})$ (Immunostained, DAB x400).

Fig 6: (a) Adult $F$. gigantica showed a negative peroxidase reaction. (b) Immunoperoxidase localization of E/S products by anti- $F$. gigantica E/S IgG pAb of adult $F$. gigantica section showed immunostain, DAB x200)

Fig 7: (a) Immunoperoxidase technique of E/S products by anti- $F$. gigantica $\mathrm{E} / \mathrm{S}$ IgG pAb in liver section of uninfected cattle, showed negative peroxidase reaction. (b) Immunoperoxidase localization of E/S products by anti- $F$. gigantica $\mathrm{E} / \mathrm{S}$ IgG pAb in liver section of $F$. gigantica heavy infected cattle showed a positive peroxidase reaction in cytoplasm of liver cells (small arrow), kupffer cells, histocytes (large arrow) in interlobular lesions and hepatocytes necrotic foci (Immunostained, DABx200).

Fig 8: (a) Immunoperoxidase technique of E/S products by anti- $F$. gigantica $\mathrm{E} / \mathrm{S}$ IgG pAb in gallbladder section of uninfected cattle showed negative peroxidase reaction. (b) Immunoperoxidase localization of E/S products by anti $F$. gigantica E/S IgG pAb in infected cattle gallbladder section, showed positivity in muscularis (arrow) and blood vessels layers (head arrow) (Immunostained, DABx200).

Fig 9: (a) Immunoperoxidase technique of E/S products by using anti- $F$. gigantica $\mathrm{E} / \mathrm{S}$ IgG pAb in small intestine section of uninfected cattle showed a negative peroxidase reaction. (b) Immunoperoxidase localization of E/S products by using anti- $F$. gigantica $\mathrm{E} / \mathrm{S}$ IgG pAb in infected cattle small intestine section, showed positivity in epithelial cells lining small intestinal glands (arrow) (Immunostained, DAB x400). Fig 10: (a) Immunoperoxidase technique of $\mathrm{E} / \mathrm{S}$ products by using anti- $F$. gigantica $\mathrm{E} / \mathrm{S}$ IgG pAb in uninfected cattle kidney section, showed a negative peroxidase reaction. (b) Immunoperoxidase localization of $\mathrm{E} / \mathrm{S}$ products by using anti- $F$. gigantica $\mathrm{E} / \mathrm{S}$ IgG pAb in infected cattle kidney section, showed a positive peroxidase reaction in cytoplasm of epithelial cells lining glomeruli (large arrow) and tubule (small arrow) (Immunostained, DAB x200).

Fig 11: (a) Immunoperoxidase technique of $\mathrm{E} / \mathrm{S}$ products by anti- $F$. gigantica $\mathrm{E} / \mathrm{S}$ IgG pAb in uninfected cattle spleen section, showed a negative peroxidase reaction. (b) Immunoperoxidase localization of E/S products by anti- $F$. gigantica $\mathrm{E} / \mathrm{S}$ IgG $\mathrm{pAb}$ in infected cattle spleen section showed a positive peroxidase reaction in lymphocytes (arrow) (Immunostained, DABx200).

Fig 12: (a) Immunoperoxidase technique of $\mathrm{E} / \mathrm{S}$ products by using anti- $F$. gigantica $\mathrm{E} / \mathrm{S}$ IgG pAb in uninfected cattle lung section, showed a negative peroxidase reaction (Immunostained, DAB X200). (b) Immunoperoxidase localization of E/S products by anti- F. gigantica E/S IgG $\mathrm{pAb}$ in infected cattle lung section showed positivity in cytoplasm of cells lining alveoli (arrow) (Immunostained, DAB x200).

Fig 13: (a) Immunoperoxidase technique of $\mathrm{E} / \mathrm{S}$ products by using anti- $F$. gigantica $\mathrm{E} / \mathrm{S}$ IgG pAb in uninfected cattle heart section, showed a negative peroxidase reaction. (b) Immunoperoxidase localization of E/S products by anti- $F$. gigantica E/S IgG pAb in heart section of $F$. gigantica infected cattle showed positivity in cytoplasm of cardiac muscle fiber (arrow) (Immunostained, DAB x200).

Fig 14: PBMNCs (a) Immunoperoxidase technique of E/S products by anti- F. gigantica E/S IgG pAb in uninfected cattle monocytes showed negative peroxidase reactions. (b) Immunoperoxidase localization of E/S products by anti- F. gigantica $\mathrm{E} / \mathrm{S}$ IgG pAb in infected cattle monocytes showed high positivity in phagolysomes, intracytoplasmic granules (large arrow) and pseudopodiae (head arrow) (Geimsa x400). Fig 15: PBMNCs (a) Immunoperoxidase technique of E/S products by anti- $F$. gigantica E/S IgG pAb in lymphocyte of uninfected cattle showed a negative peroxidase reaction. (b) Immunoperoxidase localization of E/S products by anti- F. gigantica E/S IgG pAb in lymphocyte from infected cattle showed high positivity in cytoplasm of lymphocyte (arrow) (Geimsa x400)

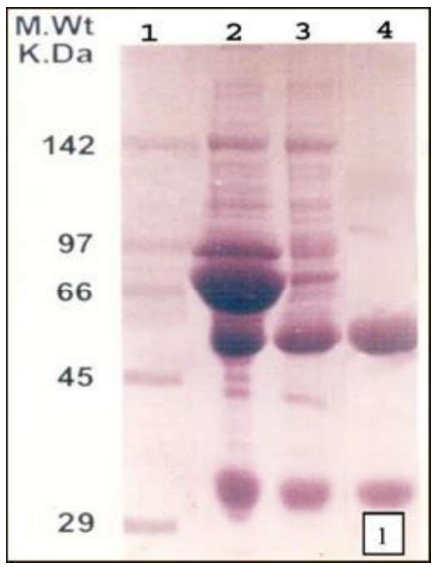



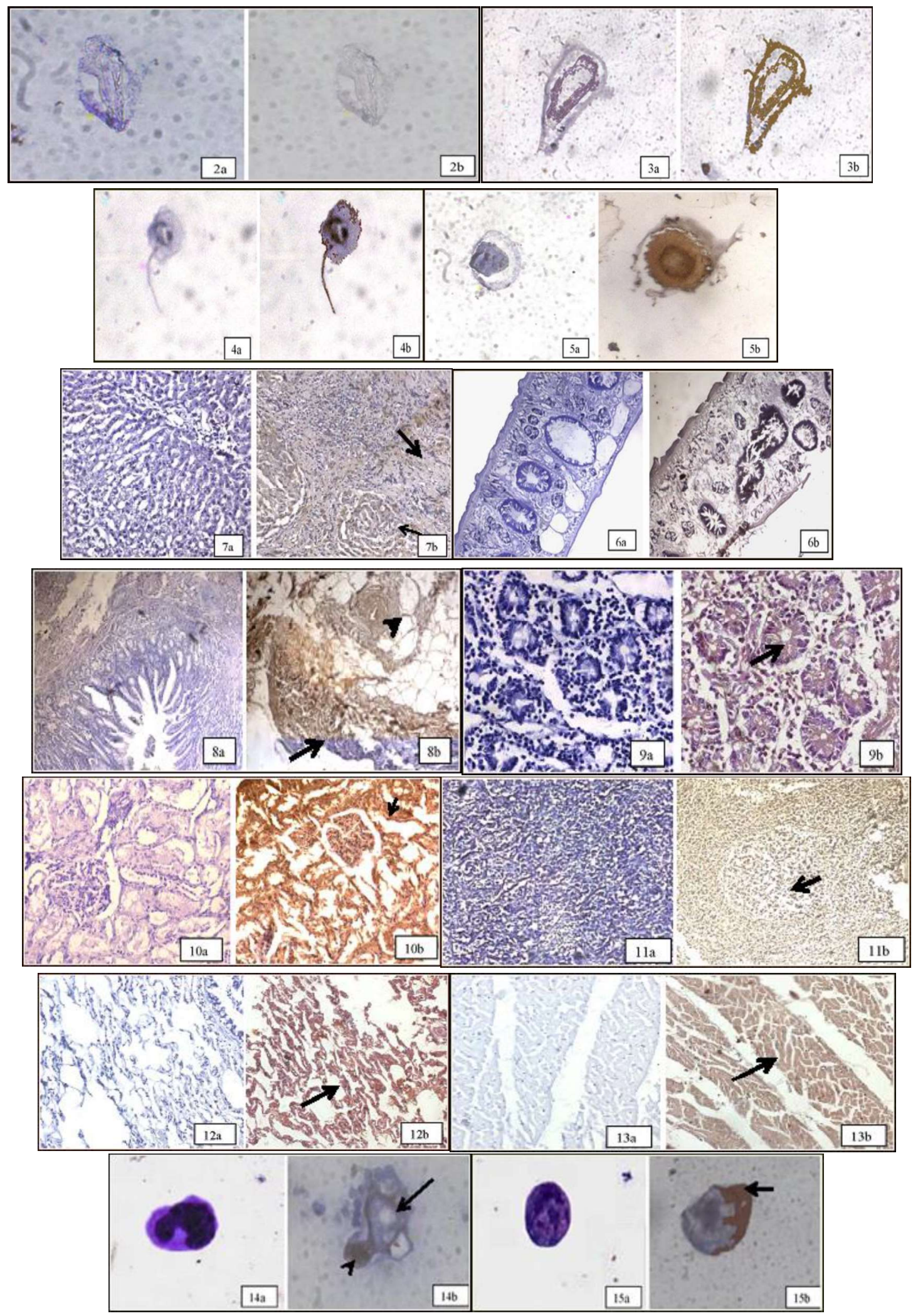